\title{
correspondence
}

\section{Travel rights}

SiR,-I was very sorry to hear of the incident involving Academician Malek's passport reported by Frantisek Janouch (6 January, page 10). Ivan Malek has been a personal friend of mine for many years and I have learned to respect his wise and humane views. Personally $I$ feel it is a tragedy that present circumstances make it very difficult for him to play the part in building up a strong, forward looking and socially concerned science in his country for which his talents so clearly qualify him.

There can be no doubt about the attitude of the World Federation of Scientific Workers toward the travel rights of scientists. I am sure Dr Janouch knows that ever since its foundation 30 years ago our Federation has worked actively for the maximum level of contacts between scientists in different countries. We fully support the UNESCO Recommendation on the Status of Scientific Researchers (1974), Article 26 of which says:

Member states should actively promote the interplay of ideas and information among scientific researchers throughout the world, which is vital to the healthy development of science and technology; and to this end should take all measures necessary to ensure that scientific researchers are enabled, throughout their careers, to participate in international scientific and technological gatherings and to travel abroad.

Following the decision of our 11 th General Assembly held in London last September, the WFSW set up a subcommittee to make these recommendations more widely known and to work actively for their practical implementation. If Dr Janouch will supply detailed, and if possible, documentary information about the incident to which he refers I am sure our subcommittee will examine it and suggest what appropriate steps, if any, the Federation should take.

$$
\text { E. H. S. BURHOP }
$$

World Federation of Scientific Workers

\section{London, $U K$}

\section{Toxic levels}

SIR,-It is not clear what are the areas of expertise of your correspondent Thomas H. Jukes (10 February, page 491). It is clear however, that one of his areas of ignorance is chemical carcinogenesis.

How does he know that "substances that are toxic at high doses are sufficiently harmless in the amounts actually present that they offer no finite hazard to health"? This is the key to the argument about carcinogenic chemicals in the environment. They give rise to tumours in significant number when tested in small groups of experimental animals for a maximum of two years. How do we extrapolate such findings to tens of millions of people whose susceptibility is unknown but might have a wide range, both above and below that of our experimental animals, and who live for 60 or 70 years?

If we reduce the doses given to our experimental animals we reach a dose at which one or two animals in a group of 100 , say, will have a tumour not seen in a group of 100 untreated controls. Although this is 1 or $2 \%$ of our population of animals (equal to 2 or 4 million of the US population), we would say that this incidence of tumours is not statistically significant, and some would claim that this dose is 'safe'. I would not. In practice, we need an incidence of tumours exceeding 5 out of 100 to be sure of statistical significance. So, because the effects of carcinogens are cumulative, we cannot establish a safe dose for any carcinogen, because we don't know how. Similarly, in our animal experiments in which we usually test single compounds we cannot take account of the probable additive or synergistic effects of several carcinogens at low doses, as we must experience them in daily life. That is why we must be wary of any carcinogen when we discover it at any level, even at the risk of appearing to be lunatic consumerists.

Perhaps Jukes should ponder the fact that there is a lot of cancer around and hundreds of thousands of people die of cancer every year, almost always of unknown cause. It is my contention that part of this cause is the carcinogenesis test which chemical manufacturers and food processors, together with Nature herself, are conducting in us, presumably with Jukes' approval.

\section{William LiJinsky} Frederick Cancer Research Center, USA

Thomas Jukes replies: Lijinsky misquotes me: my statment was " . . food contains substances that are toxic at high levels but are sufficiently harmless in the amounts actually present that they offer no finite hazard to health".
With this misquotation corrected, the basis for his peroration disappears. $\mathrm{My}$ statement was essentially a reference to the basic principle of toxicology first enunciated by Paracelsus ${ }^{1}$.

There are numerous examples of such substances, such as solanine (potatoes), cyanide (lima beans), goitrogens (cabbage), estrogens (soybeans, wheat germ), and selenium (marine fish). I am glad that Lijinsky included Nature in his list of providers of carcinogens. His discussion of the "safe dosage" of carcinogens alleges that "some would claim that this dose" (that is a dose that would produce tumours in " 2 or 4 million of the US population") "is safe". I can think of no one who would make such a claim; certainly I would not. Various authors, including myself, have discussed the problem of reaching adequately low levels of dietary carcinogens ${ }^{2-8}$.

It is certainly possible to postulate levels that pose a risk of less than one case per year in the US population, or that will not be effective unless we live for more than 200 years. However, it is not possible to devise a diet of natural foods that is free of "carcinogens", no matter whether they are "additive or synergistic" (as Lijinsky says), or even antagonistic (which he does not mention).

In his final sentence, Lijinsky incorrectly assumes that I approve of carcinogenic food additives. I favour bans on Reds No. 2 and No. 4, but I pointed out that many consumers apparently wanted to go on eating red maraschino cherries despite the findings on the dye. Many also seem to want cyclamates, saccharin and cigarettes. The current protest by consumers against banning saccharin is an effective but an unexpected support for the point I made. Consumerists wish to decide which carcinogens should be banned. Lijinsky often warns against bacon, but not against barbecueing of steaks, despite his own demonstration that this produces carcinogens ${ }^{6}$, and not against tobacco, which smoked or chewed supplies nitrosamines.

A list of my publications related to cancer is being forwarded to Lijinsky.

\footnotetext{
1 Paracelsus, Drey Bücher Heirs of Arnold Byrckmann

Cologne, 1564.
2 Jones, H. B., Grendon, A., Food and Cosmetic Toxicology, 13, 251 (1975)

Jukes, T. H. Preventive Medicine 5, 438, 1976. Cosmetic Kricology, 12,737,1975.

Cosmetic Toxicology, 12, 737, 1975. Hazards from Drugs, Evaluation of Risks, 7, 60, Springer Verlag, Berlin 1967.

6 Lijinsky, W. \& Shubik, P. Science 145, 531964.
} 